\title{
ANTIOXIDANT ACTIVITY AND CHEMICAL COMPOSITION OF SUPERCRITICAL AND CONVENTIONAL EXTRACTS OF CINNAMON (Cinnamomum cassia)
}

\author{
Amanda G. A. SÁ1 ${ }^{\text {, Sibele R. R. COMIM², Sandra R. S. FERREIRA² }}$ \\ ${ }^{1}$ Universidade Federal de Santa Catarina, Departamento de Engenharia Química e Engenharia de \\ Alimentos \\ 2 Universidade Federal de Santa Catarina, Departamento de Engenharia Química \\ E-mail: amandaa_almeidaa@hotmail.com
}

\begin{abstract}
Cinnamon is one of the most appreciated spices for flavoring food products. The objectives were to characterize cinnamon extracts and evaluate its antioxidant activities. Extraction was performed using supercritical fluid extraction (SFE), hydro-distillation (HD) and ultrasound extraction (UE). Cinnamon extract yields reached values of $8 \pm 1 \%(\mathrm{w} / \mathrm{w})$ for UE, $1.6 \pm 0.1 \%(\mathrm{w} / \mathrm{w})$ for SFE and $1.4 \pm$ $0.3 \%(\mathrm{w} / \mathrm{w})$ for HD. The antioxidant activity of extracts was evaluated by DPPH and the bleaching system $\beta$-carotene/linoleic acid $(\mathrm{C} / \mathrm{L})$. The best results of $\mathrm{EC}_{50}$ were obtained by UE with ethanol $(43 \mu \mathrm{g} / \mathrm{mL})$ and with water $(48 \mu \mathrm{g} / \mathrm{mL})$ and the best result for the $\mathrm{C} / \mathrm{L}$ method was obtained by UE with ethanol $(19 \pm 0.2 \%)$. Total phenolic content was measured by Folin Ciocalteau method and the best result was obtained by UE with water $(137 \pm 29 \mathrm{mg} \mathrm{GAE} / \mathrm{g})$. The identification of extract compounds obtained by SFE was performed by GC analysis and the main compound identified was the cinnamic aldehyde.
\end{abstract}

\section{INTRODUCTION}

The determination of the biological activity of plants and their derivatives are important to the field of natural products. Essential oils and other similar plant extracts are complex mixtures of organic compounds increasingly studied as antioxidants and antimicrobial. They have great potential to add value and define characteristics of many products. Although all parts of a plant can accumulate volatile oils, their composition may vary depending on location. The cinnamon bark is rich in cinnamic aldehyde, while the leaves and roots are rich in eugenol and camphor, respectively (Andrade et al., 2012).

Cinnamon (Cinnamomum cassia) is one of the most well known spices for flavoring food. It is used in agriculture as a fungicide and in the pharmaceutical industry as a powerful antiseptic. It presents medicinal properties like digestive, stimulant, hypotensive, sedative and vasodilator (Cemim, 2012).

Antioxidants can be defined as substances that can inhibit or retard (enzymatic or nonenzymatic) oxidation. Researches show that the cinnamon oil (Cinnamomum cassia) presents 


\section{9 a 22 de outubro de 2014 \\ Florianópolis/SC}

some phenolic compounds and the major components are cinnamic aldehyde, cinnamyl acetate and eucalyptol (Morais et al., 2009).

Therefore, the aim of the present work was to investigate the extraction of cinnamon (Cinnamomum cassia) oil by supercritical fluid extraction (SFE) with $\mathrm{CO}_{2}$, ultrasound extraction (UE) with different solvents and hydro-distillation (HD). The results were compared in terms of process yield and antioxidant activity obtained by DPPH, total phenolic content (Folin Ciocalteau) and $\beta$-carotene bleaching methods. Moreover, gas chromatography (GC) was carried out for the identification and relative quantification of the compound present in the extract obtained by SFE.

\section{MATERIALS AND METHODS}

\subsection{Raw Material and Sample Preparation}

The cinnamon (bark) used to perform the extraction was purchased at a health food store, located in Itajaí/SC, Brazil. The material was ground in a knife mill (De Leo, Porto Alegre/RS, Brazil) and characterized by size classification in a vertical vibratory sieve shaker (Bertel Metalurgic Ind. Ltda., Caieiras/SP, Brazil). For the experiments, the fraction of material used was between sieves size -20/+65 mesh. The sample was stored at $255,15 \mathrm{~K}$ in a domestic refrigerator (Freezer 250, Brastemp, São Paulo/SP, Brazil) until the extractions were performed.

\subsection{Supercritical Fluid Extraction (SFE)}

The SFE of cinnamon was performed in a dynamic extraction unit with $\mathrm{CO}_{2}$ as solvent, 99.9\% pure (White Martins, Brazil). The extraction procedure was performed in a packed bed of $15 \mathrm{~g}$ of milled material at 225 bar and $50^{\circ} \mathrm{C}$ (Maronguiu et al., 2007) with a minimum mass flow rate of $\mathrm{CO}_{2}$ of $0.2 \mathrm{~kg} / \mathrm{h}$ up to $90 \mathrm{~min}$. The extraction was collected in amber flasks and weighted in an analytical balance (AY220, Shimadzu do Brasil Ltda., São Paulo/SP, Brazil).

The yield results of SFE assay was obtained by the mean value of the duplicated experiments considering the ratio between mass of extracted oil and mass of raw material. The yield results were compared with data from the different extraction techniques (Section 2.3).

\subsection{Low Pressure Extraction (LPE)}

Ultrasound extraction (UE): The extractions were run according to Benneli et al. (2010). It was used $7 \mathrm{~g}$ of cinnamon sample and $210 \mathrm{~mL}$ of solvent, placed inside an amber flask. The extraction time was $1 \mathrm{~h}$, conducted at room temperature and performed in duplicate. The equipment used was an ultrasonic cleaner bath (Unique Ultracleaner, USC-700), which operates in a frequency of $55 \mathrm{kHz}$ and potency of $220 \mathrm{~V}$. The UE was performed with ethanol (EtOH) and distillated water (WT) with polarity of 5.2 and 9.0, respectively (Benneli et al., 2010).

Hydro-distillation (HD): The HD extraction was carried out with 50g of sample and 700 $\mathrm{mL}$ of distillated water placed inside a modified Clevenger apparatus for $6 \mathrm{~h}$ at water boiling point. 


\section{9 a 22 de outubro de 2014 \\ Florianópolis/SC}

Extracts treatment and solvent elimination: Solvents were separated from extract using reduced pressure to evaporate the solvents in a rotary evaporator (Mod. 550 e 802, Fisatom, São Paulo/SP, Brazil) obtaining the extracts. The global yield for each low pressure extraction (UE and HD) was obtained by the mean value from the duplicate experiments considering the ratio between mass of extracted oil and mass of raw material used.

\subsection{Antioxidant Activity}

The antioxidant activity was evaluated for all cinnamon extracts obtained by SFE and by LPE. Results were compared with a synthetic compound with antioxidant activity, BHT (butylated hydroxyl toluene).

Free radical scavenging activity (DPPH): The free radical scavenging activity of cinnamon extracts was evaluated using 1,1-diphenyl-2-picrylhydrazil (DPPH) radical scavenger method. Briefly, the cinnamon extract was mixed with a $0.3 \mathrm{mmol} / \mathrm{L} \mathrm{DPPH}$ ethanol solution to give final concentrations of 5, 10, 25, 50, 125, 250 and $500 \mathrm{mg} / \mathrm{mL}$ of DPPH solution. After 30 min at room temperature, the absorbance values were measured at $517 \mathrm{~nm}$ and converted into percentage of antioxidant activity (\%AA) using standard curve. DPPH is a free radical, stable at room temperature, which produces a violet solution in ethanol. In presence of antioxidant compounds the DPPH is reduced producing a non-colored solution. This activity was also expressed as the effective concentration at $50 \%\left(\mathrm{EC}_{50}\right)$, the concentration of the solution required to give a $50 \%$ decrease in the absorbance of the test solution compared to a blank solution (Mensor et al, 2001). The result data for DPPH assays were obtained considering the mean value of triplicate assays.

Total phenolic content (TPC): The TPC was determined for each extract sample according to the Folin Ciocalteau method (Singleton, 1965; Peschel et al., 2006). Briefly, the reaction mixture was composed by $0.1 \mathrm{~mL}$ of extract $(1.67 \mathrm{~g} / \mathrm{L}), 0.5 \mathrm{~mL}$ of Folin Ciocalteau reagent (a mixture of phosphomolybdate and phosphotungstate) and $1.5 \mathrm{~mL}$ of $20 \%$ sodium carbonate, placed in amber flasks. The flasks were agitated, held for $2 \mathrm{~h}$, and the absorbance was measured at $765 \mathrm{~nm}$. The TPC was calculated according to a gallic acid standard curve. The results (mean value of the triplicate assays) were expressed as milligrams of gallic acid equivalent (GAE) per gram of the extract (mg GAE/g).

$\beta$-carotene bleaching method: A model system made of $\beta$-carotene and linoleic acid undergoes a rapid discoloration in the absence of an antioxidant. The free linoleic acid radical is formed upon a hydrogen reduction by the $\beta$-carotene molecules, changing its color. The antioxidant activity from the $\beta$-carotene bleaching method was carried out according to the method described by Matthäus (2002) e Kang et al. (2006). Briefly, $40 \mathrm{mg}$ of linoleic acid and $400 \mathrm{mg}$ of Tween 20 were transferred into a flask and $1 \mathrm{~mL}$ of chloroform was added. Chloroform was removed by rotary evaporation at $40^{\circ} \mathrm{C}$. Then, $100 \mathrm{~mL}$ of distilled water was slowly added and vigorously agitated to form a stable emulsion. An aliquot of $5 \mathrm{~mL}$ of this emulsion was added to $0.2 \mathrm{~mL}$ of ethanolic cinnamon extract solution $(1.67 \mathrm{~g} / \mathrm{L})$ and the absorbance was immediately measured at $470 \mathrm{~nm}$ against a blank consisting of the emulsion without $\beta$-carotene. The tubes were placed in a water bath at $50^{\circ} \mathrm{C}$ and the absorbance was 
measured every $30 \mathrm{~min}$ up to $120 \mathrm{~min}$. The absorbance values (mean of the triplicate experiments) were converted into percentage of antioxidant activity (\%AA).

\subsection{Chemical Profile}

The identification and relative quantification of the compounds present in the cinnamon extract, obtained by SFE, and in the commercial cinnamon oil were achieved by gas chromatography (GC). The analysis was performed in a gas chromatograph (GC-2010 SHIMADZU do Brasil Ltda., São Paulo/SP, Brazil) and silica column (RTX®-WAX Crossbond ${ }^{\circledR}$ Carbowax ${ }^{\circledR}$ polyethyleneglycol - $30 \mathrm{~m}$ x 0,25 mm, 0,25 $\left.\mu \mathrm{m}\right)$.

The samples were dissolved in dichloromethane and injected for analysis. The injection mode was split, injector and detector temperature was $250^{\circ} \mathrm{C}$. The carrier gas was nitrogen at a flow rate of $40 \mathrm{~mL} / \mathrm{min}$ and the amount of sample injected was $1 \mu \mathrm{L}$. The initial column temperature was $40^{\circ} \mathrm{C}$, held for 8 minutes, then the column was heated at rate of $10^{\circ} \mathrm{C} / \mathrm{min}$ to $150^{\circ} \mathrm{C}$, this temperature was maintained for 5 minutes, and the column heated again at a rate of $10^{\circ} \mathrm{C} / \mathrm{min}$ up to $220^{\circ} \mathrm{C}$, maintained for 5 minutes. The major compounds of cinnamon were identified using commercial oil (Ferquima ${ }^{\circledR}$ ) for comparison.

\subsection{Statistical Analysis}

The global yield and antioxidant activity results were statistically evaluated by a one-way analysis of variance (ANOVA), using the Software Microsoft Excel 2007 in order to detect significant differences between values in cinnamon oil extractions by SFE and LPE, and among the percentage of antioxidant activity. The significant differences $(p<0.05)$ were analyzed by the Tukey's test.

\section{RESULTS AND DISCUSSION}

\subsection{Global Yield of SFE and LPE}

The results for extraction yield obtained by supercritical fluid extraction (SFE), ultrasound extraction (UE) with different solvents and hydro-distillation (HD) are presented in Table 1.

Table 1 - Global yield of cinnamon extracts obtained by LPE and SFE

\begin{tabular}{|c|c|c|}
\hline Extraction $^{(1)}$ & Solvent & Global yield $(\%, w / w)^{(2)}$ \\
\hline $\mathbf{U E}$ & Ethanol & $8^{\mathrm{a}} \pm 1$ \\
\hline $\mathbf{U E}$ & Water & $1.9^{\mathrm{b}} \pm 0.3$ \\
\hline HD & Water & $1.4^{\mathrm{b}} \pm 0.3$ \\
\hline SFE & $\mathrm{CO}_{2}$ & $1.6^{\mathrm{b}} \pm 0.1$ \\
\hline
\end{tabular}

(1) SFE: supercritical fluid extraction, HD: hydro-distillation, UE: ultrasound extraction.

(2) Same letters indicate no significant difference at level of $5 \%(\mathrm{p}<0.05)$. 
According to Table 1, the UE (Ethanol) extraction provided highest global yield value of 8 $\pm 1 \%(\mathrm{w} / \mathrm{w})$. The UE (Water), HD and SFE extraction are not statistically different at $5 \%$ level of significance $(\mathrm{p}<0,05)$.

Marongiu et al. (2007) studied supercritical cinnamon oil extracted with $\mathrm{CO}_{2}$ at $40^{\circ} \mathrm{C}$ and 120 bar that presented global yield of $0.8 \%(\mathrm{w} / \mathrm{w})$, a lower yield result than the value obtained in this work.

\subsection{Antioxidante Activity}

Antioxidant activity results according to analyses of DPPH, TCP (Folin Ciocalteau) and $\beta$ carotene/linoleic acid for cinnamon extracts obtained from different extraction methods (SFE and LPE) are presented in Table 2 and compared to BHT results.

Table 2 - Antioxidant activity for cinnamon extracts and BHT for different methods

\begin{tabular}{|c|c|c|c|c|c|}
\hline Extraction $^{(1)}$ & Solvent & $\% \mathbf{A A}_{\max }^{(2)}$ & $\mathrm{EC}_{50}(\mu \mathrm{g} / \mathrm{mL})^{(3)}$ & TPC (mg GAE/g) ${ }^{(4)}$ & $\% \mathbf{A A}^{(5)}$ \\
\hline $\mathbf{U E}$ & Ethanol & $93^{\mathrm{a}}$ & $43^{c}$ & $88^{\mathrm{f}} \pm 1$ & $19^{i} \pm 0.2$ \\
\hline $\mathbf{U E}$ & Water & $90^{\mathrm{a}}$ & $48^{c}$ & $137^{\mathrm{g}} \pm 29$ & $15^{\bar{i}} \pm 1$ \\
\hline HD & Water & $12^{\mathrm{b}}$ & $1013^{\mathrm{d}}$ & NR & NR \\
\hline SFE & $\mathrm{CO}_{2}$ & NR & NR & NR & $5^{\mathrm{j}} \pm 2$ \\
\hline BHT & - & $90^{\mathrm{a}}$ & $261^{\mathrm{e}}$ & $268^{\mathrm{h}} \pm 13$ & $99^{k} \pm 7$ \\
\hline
\end{tabular}

NR: not representative.

* Same letters indicate no significant difference at level of $5 \%(\mathrm{p}<0.05)$.

(1) SFE: supercritical fluid extraction, HD: hydro-distillation, UE: ultrasound extraction.

(2) Antioxidant activity evaluated by free radical scavenging activity (DPPH).

(3) Effective concentration at 50\%.

(4) Total phenolic content.

(5) Antioxidant activity evaluated by the $\beta$-carotene bleaching method.

The best $\mathrm{EC}_{50}$ results (determined by DPPH method) were obtained by UE (Ethanol) and UE (Water), although these results are not statistically different at $5 \%$ level of significance $(\mathrm{p}<$ $0.05)$.

According to Table 2, the $\mathrm{EC}_{50}$ results of $\mathrm{BHT}$ were higher than for $\mathrm{UE}(\mathrm{EtOH})$ and UE (WT), which shows that the cinnamon extracts have great potential antioxidant. However, the HD extraction for this raw material does not show satisfactory result, as the compounds responsible for the antioxidant activity of cinnamon may have suffered thermal degradation due to high temperature extraction. Moreover, SFE was not a good technique for extraction of antioxidant compounds that can be identified by the method of DPPH.

The best TPC result was obtained for UE $(137 \pm 29 \mathrm{mg} \mathrm{GAE} / \mathrm{g})$ with water. Table 2 shows that the total phenolic content of cinnamon extracts were lower than the synthetic antioxidant BHT. The HD extraction and SFE did not present good results for the extraction of phenolic compounds. 
According to Table 2, the ultrasound extraction and supercritical fluid extraction showed low antioxidant activity by $\beta$-carotene bleaching method after 120 minutes of reaction temperature of $50^{\circ} \mathrm{C}$.

\subsection{Chemical Profile}

The relative composition results for cinnamon supercritical extract and commercial oil sample are presented in Table 3 that shows the name of the identified component and the relative integrated area for the compound. The major identified component, in terms of \% area peak, was cinnamic aldehyde.

Table 3 - Chemical profile present on cinnamon extract obtained by SFE and commercial oil

\begin{tabular}{|c|c|c|c|}
\hline \multirow{2}{*}{ Compound } & \multirow{2}{*}{ RT (min) } & \multicolumn{2}{|c|}{ Relative Area \% } \\
\cline { 3 - 4 } & & Commercial Oil & SFE \\
\hline Cinnamic Aldehyde & 25 & 92 & 93 \\
\hline
\end{tabular}

(1) RT: retention time.

The chromatograms of commercial cinnamon oil and supercritical extract are presented in Figure 1 and 2, respectively.

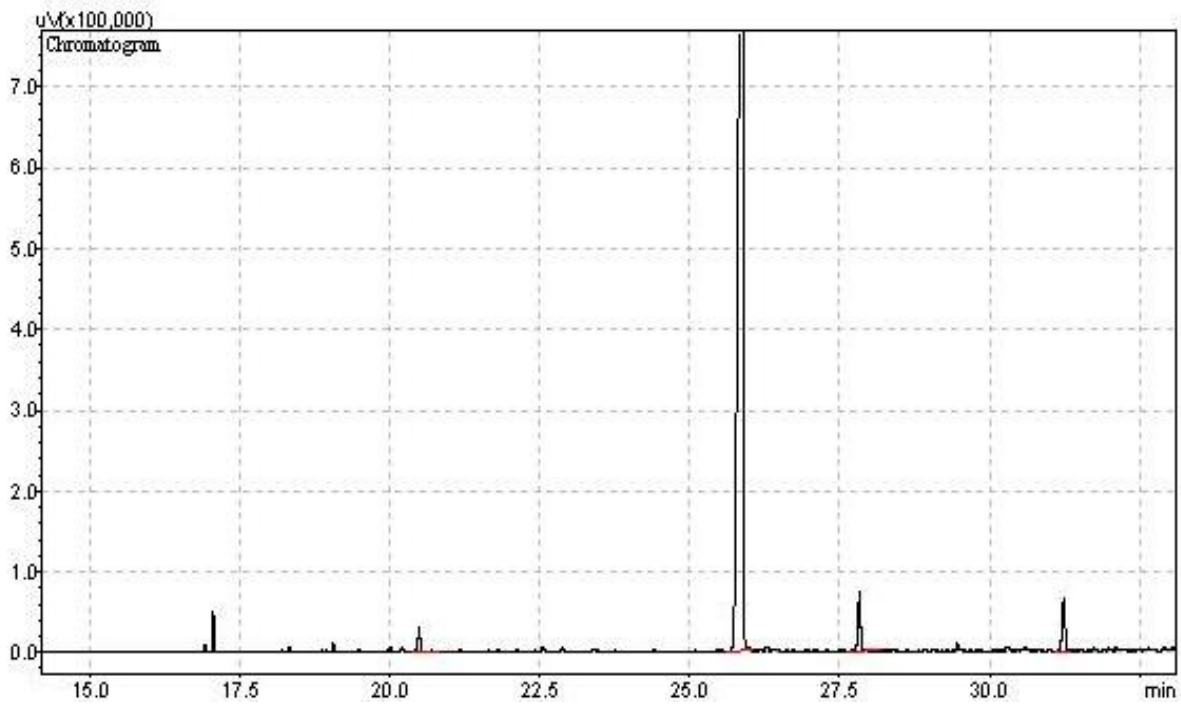

Figure 1 - Chromatogram of commercial cinnamon oil (Ferquima®). 


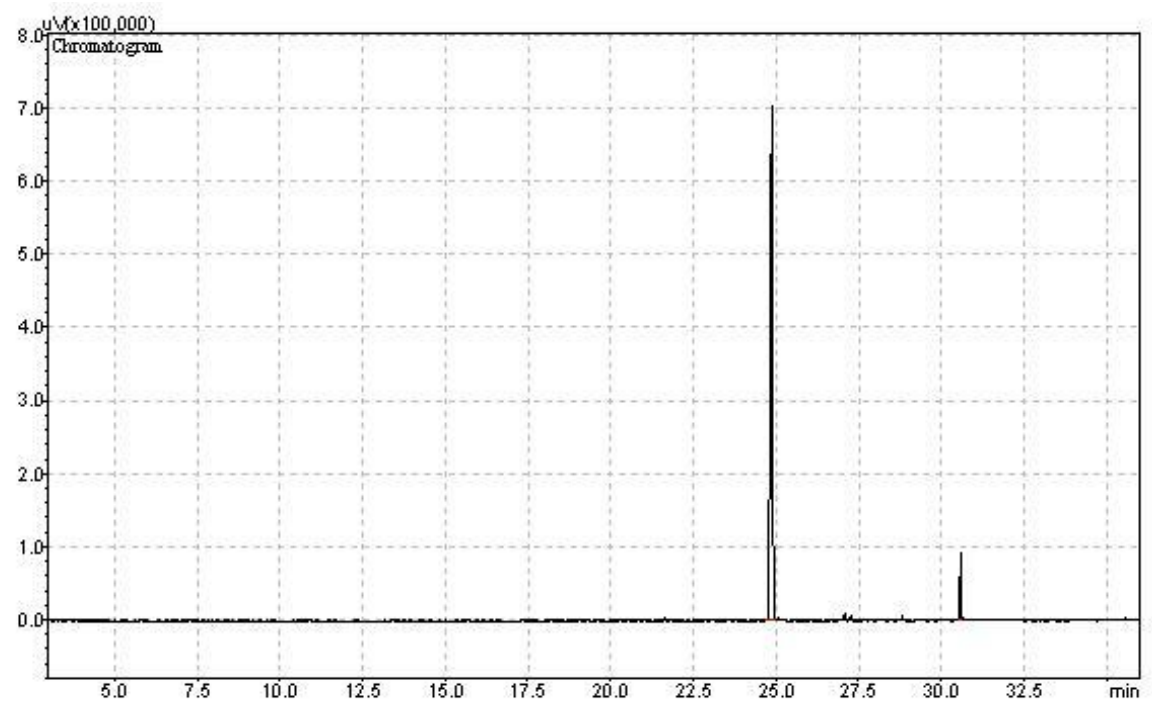

Figure 2 - Chromatogram of supercritical cinnamon extract.

\section{CONCLUSIONS}

The use of cinnamon as raw material for different extraction methods is promising due to the high quality of the substances present in its extract.

Cinnamon extraction yield reached values of $8 \pm 1 \%(\mathrm{w} / \mathrm{w})$ for ultrasound extraction using ethanol, $1.9 \pm 0.3 \%(\mathrm{w} / \mathrm{w})$ for ultrasound water extraction, $1.6 \pm 0.1 \%(\mathrm{w} / \mathrm{w})$ for supercritical extraction and $1.4 \pm 0.3 \%(\mathrm{w} / \mathrm{w})$ for hydro-distillation.

Antioxidant activity of extracts obtained by different techniques were evaluated by DPPH (2,2-diphenyl-1-picrilidrazina). Best results of $\mathrm{EC}_{50}$ were obtained for cinnamon extracts obtained by ultrasound with ethanol $(43 \mu \mathrm{g} / \mathrm{mL})$ and ultrasound with water $(48 \mu \mathrm{g} / \mathrm{mL})$. Total phenolic content was measured by Folin Ciocalteau method and the best result was obtained for water ultrasound extraction $(137 \pm 29 \mathrm{mgGAE} / \mathrm{g})$. The method of bleaching system $\beta$-carotene/linoleic was also performed, and the best result was obtained for cinnamon extract obtained by ultrasound $(19 \pm 0,2 \%)$ with ethanol.

The identification and quantification of cinnamon extract compounds obtained by supercritical extraction were performed by gas chromatography analysis and the main compound identified in terms of percentage of relative area was the cinnamic aldehyde.

\section{REFERENCES}

ANDRADE, Maria Aparecida et al. Óleos essenciais de Cymbopogon nardus, Cinnamomum zeylanicume Zingiber officinale: composição, atividades antioxidante e Antibacteriana. Rev. Ciência Agro., v. 43, n. 2, 399-408. Ceará, 2012 
BENELLI, P. et al. Bioactive extracts of orange (Citrus sinensis L. Osbeck) pomace obtained by SFE and low pressure techniques: Mathematical modeling and extract composition. J. of Supercritical Fluids, 55, p. 132-141. Florianópolis, 2010.

CEMIM, Marilaine Aurora. Atividade antifúngica do óleo essencial extraído de Cinnamomum verum sobre Candida albicans. Rev. de Bio. e Saúde da Unisep, v. 5, n.1, 27-31. São Paulo, 2012.

KANG, H. J. et al. Studies on the development of functional powder from citrus peel. Bio.Tech., v. 97, p. 614-20, 2006.

MARONGIU, Bruno. et al. Supercritical $\mathrm{CO}_{2}$ Extract of Cinnamomum zeylanicum: Chemical Characterization and Antityrosinase Activity. J. of Agricultural and Food Chem., v. 55, p. 1002210027, 2007

MATTHÄUS, B. Antioxidant activity of extracts obtained from residues of different oilseeds. $J$. of Agricultural and Food Chem. v. 50, p. 3444-52, 2002.

MENSOR, L. L. et al. Screening of Brazilian plant extracts for antioxidant activity by the use of DPPH free radical method. Phyto. Research, v. 15, p. 127-30, 2001.

MORAIS, Selene M. et al. Ação antioxidante de chás e condimentos de grande consumo no Brasil. Bra. J. of Pharma., v.19, p.315-320. Ceará, 2009.

PESCHEL, W.F. et al. An industrial approach in the search of natural antioxidants from vegetable and fruit wastes. Food Chem., 97, p.137-150, 2006.

SINGLETON, V. L. et al. Colorimetry of total phenolics with phosphomolybdic-phosphotungstic acid reagents. A. J. of Enology and Viticulture, v. 16, p. 144-58, 1965. 